\title{
HUBUNGAN PENGETAHUAN DAN PERSONAL HYGINE TERHADAP KEJADIAN KEPUTIHAN PADA SISWI SMA
}

\author{
Krisna Delita ${ }^{1}$, Ahmad Arif ${ }^{1}$, Intan Ria Sari², Intan Permata Sari² \\ Program Studi Diploma IV Kebidanan Universitas Kader Bangsa \\ Jl. Mayjend. H.M Ryacudu No.88 Ulu Palembang, Sumatera Selatan-Indonesia \\ Email: krisnadelita30@gmail.com
}

\begin{abstract}
Abstrak
Keputihan merupakan cairan yang berlebihan yang keluar dari vagina. Keputihan bisa bersifat fisiologis (normal) dan patologis (akibat penyakit). Tujuan penelitian ini adalah untuk mengetahui Hubungan Pengetahuan Dan Personal Hygine Terhadap Kejadian Flour Albus Pada Siswi SMA Negeri 5 Prabumulih Tahun 2019. Metode penelitian yang digunakan adalah Survey Analitik dengan pendekatan Cross Sectional. Populasi pada penelitian ini adalah semua siswi SMA Negeri 5 Prabumulih yang berjumlah 294 orang. Sampel penelitian ini sebanyak 163 orang. Instrumen yang digunakan dalam penelitian ini yaitu lembar angket. Analisis yang digunakan adalah analisis univariat dan bivariat. Hasil penelitian berdasarkan analisis univariat diketahui bahwa dari 163 responden terdapat 117 responden (71,8\%) yang memiliki pengetahuan baik, 46 responden $(28,2 \%)$ yang memiliki pengetahuan kurang baik, terdapat 143 responden (87,7\%) yang mlakukan personal hygine baik, 20 responden (12,3\%) yang melakukan personal hygine buruk dan 138 responden (84,7\%) yang mengalami keputihan fisiologis, 25 responden $(15,3 \%)$ yang mengalami keputihan patologis. Hasil analisis bivariat didapatkan hubungan antara pengetahuan ( $p$ value $=0,000)$ dan personal hygine ( $p$ value $=0,000)$ terhadap kejadian flour albus (keputihan). Kesimpulan dari penelitian ini adalah bahwa ada hubungan yang bermakna antara Pengetahuan dan Personal Hygine Terhadap Kejadian Flour Albus (Keputihan) Pada Siswi SMA Negeri 5 Prabumulih Tahun 2019.
\end{abstract}

Kata kunci : Flour albus (keputihan), pengetahuan, personal hygine

\section{Abstract}

Vaginal discharge is excessive fluid that comes out of the vagina. Leucorrhoea can be physiological (normal) and phatological (due to disease). The purpose of this study was to determine the relationship between Knowledge and Personal Hygine in Prabumulih 5 High Scool Students in 2019. The research method used was analytic survey with cross-sectional approach. The population in this study were all 294 students of Prabumulih State Senior High Scool. The sampel of this study was 163 people. The instument used in this study is the questionnaire sheet. The analysis used is univariate and bivariate analysis. The results of the study based on univariate analysis revealed that of 163 respondents there were 117 respondents (71,8\%) who had goor knowledge, 46 respondents $(28,2 \%)$ who had poor knowledge, there were 143 respondents $(87,7 \%)$ who did good personal hygine, 20 respondents $(12,3 \%)$ did personal hygine badly and 138 respondents (84,7\%) who experienced physiological vaginal discharge, 25 respondents experienced pathological vaginal discharge. The results of bivariate analysis found a relationship between knowledge $(P$ value $=0,000)$ and personal hygine $(P$ value $=0,000)$ to the incidence of flour albus (Vaginal discharge). The conclusion of this study is that there is a significant relationship between Knowledge and Personal hygine Against Flour Albus (Vaginal discharge) in Students of Prabumulih 5 High School in 2019.

Keywords : Flour Albus (Vaginal discharge), knowledge, personal hygine 


\section{PENDAHULUAN}

Menurut WHO (2010) keputihan menyerang sekitar $50 \%$ populasi perempuan dan mengenai pada semua umur. Data penelitian tentang kesehatan reproduksi wanita menunjukkan $75 \%$ wanita di dunia pasti menderita keputihan, paling tidak sekali seumur hidup dan $45 \%$ di antaranya bisa mengalaminya sebanyak dua kali atau lebih, sedangkan wanita Eropa yang mengalami keputihan sebesar $25 \%$.

Menurut WHO perempuan jarang dalam memperhatikan kebersihan pada organ genitalia eksternanya. Infeksi pada vagina setiap tahunnya menyerang perempuan diseluruh dunia 10-15\% dari 100 juta perempuan. Contohnya remaja yang terkena infeksi bakteri candida sekitar $15 \%$ dan mengalami keputihan. Kejadian tersebut dikarenakan remaja tidak mengetahui permasalahan seputar organ reproduksi (Utami, 2014).

Di Indonesia sekitar 90\% wanita berpotensi mengalami keputihan karena negara Indonesia adalah daerah yang beriklim tropis, sehingga jamur mudah tumbuh dan berkembang yang mengakibatkan banyaknya kasus keputihan. Gejala keputihan juga dialami oleh wanita yang belum kawin atau remaja putri yang berumur 15-24 tahun yaitu sekitar 31,8\%. Hal ini menunjukan remaja lebih beresiko terkena keputihan (Azizah, 2015).

Berdasarkan data dinas kesehatan Provinsi Sumatera Selatan pada tahun 2011 jumlah remaja putri yaitu 2,9 jiwa berusia 15-24 tahun, diantaranya $45 \%$ pernah mengalami flour albus (keputihan). Penderita yang sakit dalam keadaan stadium lanjut, kanker mulut rahim di awali dengan flour albus (keputihan) yang lama tidak di obati (Dinkes, 2010).

Mengemukakan keputihan sebagai gejala yang sangat sering di alami oleh sebagian besar wanita. Gangguan ini merupakan masalah kedua sesudah gangguan haid. Keputihan bisa jadi indikasi adanya penyakit. Hampir semua perempuan pernah mengalami keputihan. Keputihan dapat menjadi manifestasi dari semua penyakit organ reproduksi (Depkes, 2010).

Cakupan persentase kesedian alat informasi dan media penyuluhan pada remaja tentang kesehatan reproduksi kota prabumulih yaitu sebesar 90\%. Sasaran strategis yaitu tercapainya perubahan perilaku dan kemandirian untuk hidup sehat (Dinkes Kota Prabumulih, 2016).

Keputihan merupakan cairan yang berlebihan yang keluar dari vagina. Keputihan bisa bersifat fisiologis (normal) dan patologis (akibat penyakit). Keputihan fisiologis biasanya terjadi pada masa subur serta sebelum dan sesudah haid. Normal saja bila pada masa-masa tersebut banyak cairan yang keluar dari vagina anda. Selama ciran tersebut tidak berbau dan tidak menyebabkan gatal. Keputihan patologis merupakan keputihan yang disebabkan oleh infeksi vagina, adanya benda asing dalam vagina, atau protozoa. Keputihan patologis biasanya berwarna seperti susu atau hijau kekuning-kuningan, atau bercampur darah jika keputihan sudah menjadi penyakit. Bila sudah menjadi penyakit biasanya keputihan patologis menyebabkan gatal pada daerah vagina, berbau, dan menyebabkan rasa tidak nyaman (Irianto, 2014).

Hasil penelitian Kursani, dkk (2015) yang berjudul Faktor-Faktor Yang Mempengaruhi Terjadinya Flour Albus (Keputihan) Pada Remaja Putri Di SMA PGRI Pekanbaru Tahun 2013. Berdasarkan hasil uji statistik diperoleh $P$ value semua variabel $<\alpha(0,05)$, berarti terdapat hubungan yang signifikan antara pengetahuan, sikap, personal hygine, dan douching dengan terjadinya flour albus. Berdasarkan hasil uji statistik diperoleh nilai OR yang paling tinggi diantara variabel yang lain adalah variabel pengetahuan dengan nilai OR $(95 \% \mathrm{CI})=9,900(1,696$ 57,778), artinya responden yang memiliki tingkat pengetahuan rendah berpeluang 9,900 kali terjadinya flour albus tidak normal dibandingkan responden yang memiliki tingkat pengetahuan tinggi. 
Hasil penelitian dari Tresnawati (2014) yang berjudul Hubungan Personal Hygine Dengan Terjadinya Keputihan Pada Remaja Putri. Hasil analisis hubungan personal hygine dengan terjadinya keputihan pada remaja putri lebih banyak terjadi $(93,1 \%)$ pada remaja putri yang memiliki personal hygine buruk, dibandingkan dengan terjadinya keputihan yang memiliki personal hygine baik $(22,2 \%)$. Hasil uji statistik dengan menggunakan chi square pada $\alpha=$ 0,05 didapatkan nilai $P$ sebesar $0,000(P<$ $0,05)$ yang bearti bahwa secara statistik terdapat hubungan personal hygine dengan terjadinya keputihan pada remaja putri di SMAN 3 Rangkasbitung tahun 2014. Dan diperoleh CI 9.191-242.898 dan Odd Ratio 47,250 artinya terjadinya keputihan pada remaja putri yang personal hyginenya buruk memiliki 47 kali lebih besar dibandingkan dengan remaja putri yang personal hyginenya baik.

Menurut data yang didapatkan dari SMA Negeri 5 Prabumulih pada tahun 2019 jumlah seluruh siswi adalah 294. Berdasarkan data tersebut maka peneliti tertarik untuk melakukan penelitian tentang "Hubungan Pengetahuan Dan Personal Hygine Terhadap Kejadin Flour Albus (Keputihan) Pada Siswi SMA Negeri 5 Prabumulih Tahun 2019”.

\section{METODE PENELITIAN}

Penelitian ini menggunakan penelitian kuantitatif dengan pendekatan crosssectionel. Desain penelitian yang digunakan dalam penelitian ini adalah survey analitikyang digunakan untuk menjelaskan suatu situasi/keadaan.

\section{Waktu dan Tempat Penelitian}

Penelitian ini dilakukan pada bulan April-Juni Tahun 2019 dan tempat penelitian ini dilaksanakan di SMA Negeri 5 Prabumulih.

\section{Populasi dan Sampel}

Populasi dalam penelitian ini adalah semua siswi SMA Negeri 5 Prabumulih yang berjumlah 294 orang. Teknik pengambilan sampel total sampling dengan jumlah sampel sebanyak 163 siswi. Prosedur penelitian ini responden mengisi lembar informed consent yang disediakan oleh peneliti dan pada penelitian ini menggunakan teknik sebelumnya sudah diberikan penjelasan oleh peneliti tentang maksud dan tujuan penelitian serta tata cara pengisian lembar tersebut, serta peneliti juga menjelaskan kerahasiaan responden untuk disimpan oleh peneliti dan tidak dipublikasikan. Penelitian ini menggunakan data primer. Instrumen yang digunakan dalam penelitian ini berupa lembar angket tentang pengetahuan dan personal hygine siswi terhadap kejadian flour albus (keputihan).

\section{HASIL PENELITIAN DAN PEMBAHASAN}

Tabel. 1

Distribusi Frekuensi Dan Persntase Responden Berdasarkan Pengetahuan Siswi

\begin{tabular}{|c|c|}
\hline No Pengetahuan & Frekuensi \\
\hline $\begin{array}{ll}1 & \text { Baik }\end{array}$ & 117 \\
\hline 2 kurang & 28,2 \\
\hline 3 Jumlah & 100,0 \\
\hline
\end{tabular}

Berdasarkan tabel di atas dari 163 responden terdapat 117 responden $(71,8 \%)$ yang memiliki pengetahuan baik, 46 responden $(28,2 \%)$ yang memiliki pengetahuan kurang baik

Tabel. 2

Distribusi Frekuensi Dan Persntase Responden Berdasarkan Personal Hygine Siswi

\begin{tabular}{llcc}
\hline No Personal Hygine & Frekuensi & $(\%)$ \\
\hline 1 & Baik & 143 & 87,7 \\
2 & Buruk & 20 & 12,3 \\
& & & \\
\hline 3 & Jumlah & 163 & 100,0 \\
\hline
\end{tabular}

Berdasarkan tabel di atas, dari 163 responden terdapat 143 responden $(87,7 \%)$ yang melakukan personal hygine secara baik, 20 responden $(12,3 \%)$ yang melakukan personal hygine secara buruk. 
Tabel. 3

Distribusi Frekuensi Dan Persntase Responden Berdasarkan Keputihan Siswi

\begin{tabular}{llcc}
\hline No Keputihan & Frekuensi & $\mathbf{( \% )}$ \\
\hline 1 & Fisiologis & 138 & 85,3 \\
2 & Patologis & 25 & 14,7 \\
& & & \\
\hline 3 & Jumlah & 163 & 100,0 \\
\hline
\end{tabular}

Berdasarkan tabel di atas, dari 163 responden terdapat 139 responden $(85,3 \%)$ yang mengalami keputihan fisiologis, 25 responden (14,7\%) yang mengalami keputihan patologis.

Tabel. 4

Hubungan Pengetahuan Terhadap Kejadian Keputihan PadaSiswi

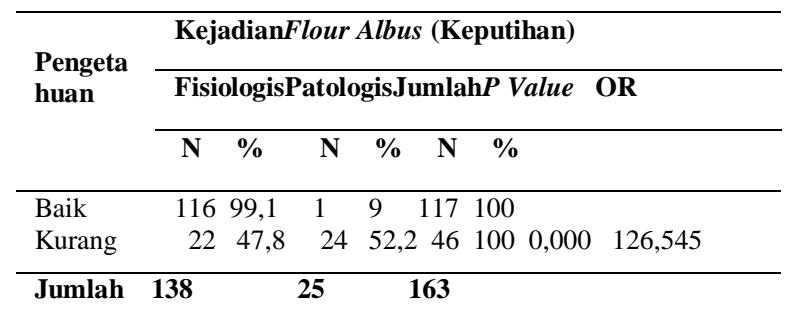

Dari tabel di atas bahwa dari 163 responden yang memiliki pengetahuan baik dengan keputihan fisiologis sebanyak 116 responden $(99,1 \%)$, yang mengalami keputihan patologis sebanyak 1 responden (9\%) dan yang memiliki pengetahuan kurang baik dengan keputihan fisiologis sebanyak 22 responden (47,8\%), yang mengalami keputihan patologis sebanyak 24 responden $(52,2 \%)$.

Tabel. 5

Hubungan Personal Hygine Terhadap Kejadian Keputihan Pada Siswi

\begin{tabular}{|c|c|}
\hline \multirow{3}{*}{$\begin{array}{c}\text { Personal } \\
\text { Hygine }\end{array}$} & KejadianFlour Albus (Keputihan) \\
\hline & FisiologisPatologisJumlahP ValueOR \\
\hline & $\begin{array}{llll}\mathbf{N} & \% & \mathbf{N} & \%\end{array}$ \\
\hline Baik & $13795,864,2 \quad 143100$ \\
\hline Buruk & $20 \quad 100 \quad 0,000433,833$ \\
\hline Jumlah 138 & 163 \\
\hline
\end{tabular}

Dari tabel di atas bahwa dari 163 responden yang melakukan personal hygine secara baik dengan keputihan fisioligis sebanyak 137 responden $(95,8 \%)$, yang mengalami keputihan ptologis sebanyak 6 responden $(4,2 \%)$ dan yang melakukan personal hygine secara buruk dengan keputihan fisioligis sebanyak 1 responden $(5,0)$, yang mengalami keputihan patologis sebanyak 19 responden $(95,0 \%)$.

\section{Hubungan Pengetahuan Terhadap Kejadian Keputihan.}

Berdasarkan hasil penelitian dapat diketahui bahwa dari 163 responden terdapat 117 responden $(71,8 \%)$ yang memiliki pengetahuan baik, 46 responden $(28,2 \%)$ yang memiliki pengetahuan kurang baik.

Pada analisis bivariat dari 163 responden yang memiliki pengetahuan baik dengan keputihan fisiologis sebanyak 116 responden $(99,1 \%)$, yang mengalami keputihan patologis sebanyak 1 responden (9\%) dan yang memiliki pengetahuan kurang baik dengan keputihan fisiologis sebanyak 22 responden $(47,8 \%)$, yang mengalami keputihan patologis sebanyak 24 responden $(52,2 \%)$.

Hasil uji statistik chi-square didapatkan $p$ value $=0,000$ lebih kecil dari 0,05, maka menunjukkan bahwa ada hubungan secara parsial antara pengetahuan terhadap kejadian flour albus (keputihan) pada siswi SMA Negeri 5 Prabumulih tahun 2019. Dengan demikian hipotesis menyatakan ada hubungan yang bermakna antara pengetahuan terhadap kejadian keputihan dan sudah terbukti secara statistik.

Penelitian ini sejalan dengan teori yang menyatakan bahwa kekurangan informasi dan pengetahuan tentang perubahan sistem reproduksi pada usia remaja menimbulkan kecemasan dan rasa malu karena berbeda dengan teman sebayanya. Hal ini, mengakibatkan timbul bermacam masalah yang berhubungan dengan alat reproduksi mereka. Salah satunya adalah munculnya keputihan pada remaja (Dhuangga, dkk, 2012). 
Hasil penelitian dari Mokodongan, dkk (2015) yang berjudul Hubungan Tingkat Pengetahuan Tentang Keputihan Dengan Perilaku Pencegahan Keputihan Pada Remaja Putri. Hasil statistik menunjukkan bahwa ada hubungan antara tingkat pengetahuan tentang keputihan dengan perilaku pencegahan keputihan pada remaj $(P=0,023)$. Remaja dengan tingkat pengetahuan tentang keputihan yang baik memiliki kecenderungan 1,5 kali memiliki perilakupencegahan keputihan yang baik $(\mathrm{PR}=1.5: 95 \% \mathrm{CI}=1,1-2,2)$.

Hasil penelitian Kursani, dkk (2015) yang berjudul Faktor-Faktor Yang Mempengaruhi Terjadinya Flour Albus (Keputihan) Pada Remaja Putri Di SMA PGRI Pekanbaru Tahun 2013. Berdasarkan hasil uji statistik diperoleh $P$ value semua variabel $<\alpha(0,05)$, berarti terdapat hubungan yang signifikan antara pengetahuan, sikap, personal hygine, dan douching dengan terjadinya flour albus. Berdasarkan hasil uji statistik diperoleh nilai OR yang paling tinggi diantara variabel yang lain adalah variabel pengetahuan dengan nilai OR $(95 \% \mathrm{CI})=9,900(1,696-$ 57,778 ), artinya responden yang memiliki tingkat pengetahuan rendah berpeluang 9,900 kali terjadinya flour albus tidak normal dibandingkan responden yang memiliki tingkat pengetahuan tinggi.

Berdasarkan hasil penelitian di atas, maka peneliti berasumsi bahwa siswi yang memiliki pengetahuan buruk berpotensi lebih besar mengalami keputihan yang ptologis dan apabila hal tersebut tidak segera diatasi maka akan menyebabkan kanker serviks atau kelainan pada alat genita lainnya.

\section{Hubungan Personal Hygine Terhadap Kejadian Keputihan.}

Berdasarkan hasil penelitian dari 163 responden terdapat 143 responden $(87,7 \%)$ yang melakukan personal hygine secara baik, 20 responden $(12,3 \%)$ yang melakukan personal hygine secara buruk.

Pada analisis bivariat dari dari 163 responden yang melakukan personal hygine secara baik dengan keputihan fisioligis sebanyak 137 responden (95,8\%), yang mengalami keputihan ptologis sebanyak 6 responden $(4,2 \%)$ dan yang melakukan personal hygine secara buruk dengan keputihan fisioligis sebanyak 1 responden $(5,0)$, yang mengalami keputihan patologis sebanyak 19 responden $(95,0 \%)$.

Hasil uji statistik chi-square didapatkan $p$ value $=0,000$ lebih kecil dari 0,05, maka menunjukkan bahwa ada hubungan secara parsial antara personal hygine terhadap kejadian flour albus (keputihan) pada siswi SMA Negeri 5 Prabumulih tahun 2019. Dengan demikian hipotesis menyatakan ada hubungan yang bermakna antara personal hygine terhadap kejadian keputihan dan sudah terbukti secara statistik.

Penelitian ini sejalan dengan teori yang menyatakan personal hygine yang baik dan buruk dapat mempengaruhi organ reproduksi pada remaja, tindakan pencegahan keputihan pada remaja putri juga semakin baik dalam menjaga kesehatan reproduksi. Sebaliknya jika remaja putri kurang memiliki pengetahuan tentang personal hygine maka tindakan pencegahan keputihan juga berlangsung kurang baik. Banyak gangguan kesehatan yang diderita seseorang karena tidak terpeliharanya kebersihan perseorangan dengan baik (Permatasari, dkk, 2012).

Hasil penelitian dari Tresnawati (2014) yang berjudul Hubungan Personal Hygine Dengan Terjadinya Keputihan Pada Remaja Putri. Hasil analisis hubungan personal hygine dengan terjadinya keputihan pada remaja putri lebih banyak terjadi $(93,1 \%)$ pada remaja putri yang memiliki personal hygine buruk, dibandingkan dengan terjadinya keputihan yang memiliki personal hygine baik $(22,2 \%)$. Hasil uji statistik dengan menggunakan chi square pada $\alpha=$ 0,05 didapatkan nilai $P$ sebesar $0,000(P<$ $0,05)$ yang bearti bahwa secara statistik terdapat hubungan personal hygine dengan terjadinya keputihan pada remaja putri di SMAN 3 Rangkasbitung tahun 2014. Dan diperoleh CI 9.191-242.898 dan Odd Ratio 47,250 artinya terjadinya keputihan pada remaja putri yang personal hyginenya buruk 
memiliki 47 kali lebih besar dibandingkan dengan remaja putri yang personal hyginenya baik.

Hasil penelitian Ilmiawati dan kuntoro (2016), yang berjudul Pengetahuan Personal Hygine Remaja Putri Pada Kasus Keputihan. Diketahui bahwa sebagian besar responden memiliki pengetahuan yang tidak baik sebesar 23 responden (46\%) tentang personal hygine. Tidak ada responden yang memiliki pengetahuan baik tentang personal hygine. Sedangkan untuk yang memiliki pengetahuan cukup sebanyak 14 responden (28\%) dan kurang baik 13 responden (26\%).

Berdasarkan hasil penelitian di atas, maka peneliti berasumsi bahwa siswi yang melakukan personal ygine buruk seperti jarang mengganti pakaian dalam, jarang mengganti pembalut pada saat menstruasi, cara mencuci kemaluan yang salah, menggunakan pakaian dalam yang berbahan nylon dan sering menggunakan cairan sabun pembersih vagina. Hal inilah yang menyebabkan adanya bakteri jahat dan jamur masuk kedalam vagina sehingga menyebabkan keputihan.

\section{KESIMPULAN}

Dari hasil penelitian yang dilakukan di SMA Negeri 5 Prabumulih tahun 2019 tentang Hubungan Pengetahuan dan Personal Hygine Terhadap Kejadian Flour Albus (Keputihan) Pada Siswi SMA Negeri 5 Prabumulih Tahun 2019, maka peneliti menarik beberapa kesimpulan yang berkaitan dengan variabel yang diteliti dengan jumlah responden 163 siswi yaitu:

1. Ada Hubungan Pengetahuan dan Personal Hygine Secara Simultan Terhadap Kejadian Flour Albus (Keputihan) Pada Siswi SMA Negeri 5 Prabumulih Tahun 2019.

2. Ada Hubungan Pengetahuan Secara Parsial Terhadap Kejadian Flour Albus (Keputihan) Pada Sisiwi SMA Negeri 5 Prabumulih Tahun 2019.

3. Ada Hubungan Personal Hygine Secara Parsial Terhadap Kejadian Flour Albus
(Keputihan) Pada Sisiwi SMA Negeri 5 Prabumulih Tahun 2019.

\section{SARAN}

\section{Bagi Siswi Sekolah SMA Negeri 5 Prabumulih}

Berdasarkan data yang telah didapatkan dari SMA Negeri 5 Prabumulih, maka penulis menyarankan untuk siswi SMA agar banyak membaca buku tentang kesehatan reproduksi pada remaja dan lebih memperhatikan lagi kebersihan diri sendiri terutama pada alat genitalianya guna mencegah terjadinya keputihan dan mencegah hal-hal yang tidak di inginkan.

\section{Bagi Universita Kader Bangsa}

Diharapkan dapat meningkatkan pengetahuan, kemampuan dan keterampilan mahasiswa dalam menerapkan studi yang telah didapat, serta dapat melengkapi sumber-sumber buku perpustakaan sebagai bahan informasi dan referensi yang penting dalam pembuatan skripsi.

\section{Bagi Peneliti}

Diharapkan agar dapat meningkatkan pengetahuan tentang flour albus (keputihan) serta dapat menerapkannya pada diri sendiri, keluarga dan masyarakat.

\section{Bagi Peneliti Yang Akan Datang}

Diharapkan dapat melanjutkan penelitian tentang Hubungan Pengetahuan Dan Personal Hygine Terhadap Kejadian Flour Albus (Keputihan). Agar dapat menyempurnakan rancangan penelitian ini, sehingga dapat diperoleh pemahaman yang lebih mendalam mengenai flour albus (keputihan). 


\section{DAFTAR PUSTAKA}

Azizah, N. 2015. Karakteristik Remaja Putri dengan Kejadian Keputihan Di SMK Muhammadiyah Kudus. Jurnal Ilmu Keperawatan dan Kebidanan. Vol 6. No. 1. Diakses tanggal 27 April 2019.

Depkes Palembang. 2010. Profil Kesehtan KotaPalembang.http://www.depkes.g o.id. Diakses tanggal 27 April 2019.

Dinkes Sumatera Selatan. 2010. Profil Kesehatan Sumatera Selatan. http://www.dinkes.palembang.co.od. Diakses tanggal 27 April 2019.

Dinkes Prabumulih. 2016. Visi dan Misi Dinas Kesehatan Kota Prabumulih. http://www.kotaprabumulih.go.id. Diakses tanggal 27 April 2019.

Dhuangga, dkk. 2012. Efektifitas Pendidikan Kesehatan Tentang Hygine Kewanitaan Terhadap Pengetahuan Dan Sikap Remaja Putri Dalam Menangani Keputihan. Jurnal Ners Indonesia 2 (2).

Ilmawati, H dan Kuntoro. 2016. Pengetahuan Personal Hygine Remaja Putri Pada Kasus Keputihan. Jurnal Biometika dan Kependudukan, Vol. 5, No. 1 Juli 2016: 43-51

Irianto, Koes. 2014. Epidemiologi Penyakit Menular dan Tidak Menular. Bandung: Alfabeta.
Kursani, E, Mrlina, H, Olfa, K. 2015. Faktor-Faktor yang Mempengaruhi Terjadinya Flour Albus Keputihan) Pada Remaja Putri di SMA PGRI Pekanbaru. Jurnal Maternity and Neonatal Volume 2 No.1: 30-36.

Mokodongan, MH, Wantani, J, Wagey, F. 2015. Hubungan Pengetahuan Tentang Keputihan Dengan Perilaku Pencegahan Keputihan Pada Remaja Putri. Jurnal e-Clinic (eCl), Volume 3, No 1, Januari-April 2015: 272-276.

Permatasari, dkk. 2012. Daya Hambat Perasan Daun Sirsak Terhadap Pertumbuhan Bakteri Escherichia Coli. Jurnal Fakultas Kedokteran Hewan. Bali: Universitas Udayana.

Tresnawati, W dan Rachmatullah, F. 2014. Hubungan Personal Hygine dengan Terjadinya Keputihan Pada Remaja Putri. Jurnal Penelitian Kesehatan. Diakses tanggal 27 April 2019.

Utami. Dkk. 2014. Faktor-Faktor yang Mempengaruhi Kualitas Hidup Pasien Militus dengan Ulkus Diabetikus. JOM PSIK 1 (2), 1-7. Diakses tanggal 27 April 2019.

WHO. 2010. Infant Mortanity World Health Organization.

http://www.who.int/.whr/2010/en/in dex.html. Diakses tanggal 27 April 2019. 